\title{
CIUDAD ACCESIBLE: \\ Nociones y criterios de diseño. Caso Bogotá (Colombia)
}

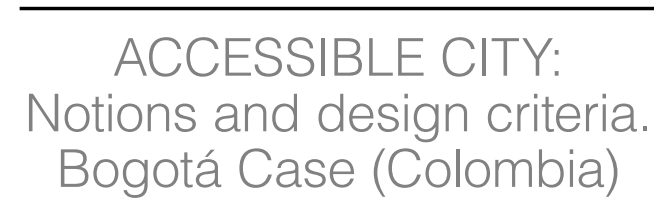

DOI: 10.179 81/mod.arq.cuc.18.1.2017.06

Fecha de Envío: 25 de agosto de 2017 Fecha de Aceptación: 27 de octubre de 2017

\section{Jennifer Cañaveral Guzmán}

IDU - Instituto de Desarrolllo Urbano Bogotá / Universidad Nacional de Colombia. jenarq85@gmail.com

Para citar este artículo:

Cañaveral, J. (2017). CIUDAD ACCESIBLE: Nociones y criterios de diseño. Caso Bogotá (Colombia).. MODULO ARQUITECTURA-CUC, vol. 18, no. 1, pp. 109-132. DOI: 10.17981/mod.arq.cuc.18.1.2017.06

\section{Resumen}

El presente trabajo presenta un análisis de los criterios para considerar la ciudad accesible. Pretende, además, plantear aspectos para la ordenación de la accesibilidad urbanística y formular una política pública para la ciudad accesible que esté adecuada a las necesidades de las personas con diferentes discapacidades. Esta investigación se enfoca en el estudio de las problemáticas urbanas de dos localidades en Bogotá: Teusaquillo y Barrios Unidos, especialmente, la zona delimitada entre la calle 57 y la calle 67 a lo largo de la carrera 17, y en la generación de propuestas orientadas a la mejora de la movilidad para las personas en condición de discapacidad, contribuyendo a optimizar las condiciones de movilidad del sector y, así, la población con discapacidades pueda tener una excelente calidad de vida. Asimismo, se apunta a la mejora del transporte público y la creación de nuevos espacios verdes en la ciudad con miras a un nuevo modelo urbanístico sostenible e integral.

Palabras clave: movilidad peatonal, accesibilidad, inclusión social

\section{Abstract}

This documents aims at analyzing and planning the "notions and criteria of the accessible city". Therefore, the objective is to examine and plan urban accessibility to formulate a public policy for an accessible city that meets the needs of people with different disabilities. This research focuses on the study of the urban problems of two localities in Bogotá: Teusaquillo and Barrios Unidos, mainly the area delimited between 57th street and 67th street along the 17 avenue. In addition, the study suggests the generation of proposals aimed at improving mobility for people in the condition of disability in order to help improve the mobility conditions of the sector and, hence, provide an excellent quality of life to the population with disabilities. Likewise, this paper advises on the improvement of public transportation and the creation of new green spaces in the city so as to move towards a new sustainable and comprehensive urban model.

Keywords: Pedestrian mobility, accessibility, social inclusion 


\section{INTRODUCCIÓN}

La evolución de la ciudad y su historia en relación con la accesibilidad ha generado dos instancias en términos urbanos: lo privado y lo público. Los espacios privados son aquellos lugares que están delimitados o predios donde se desarrollan las actividades privadas; y los espacios públicos, son aquellos sitios de congregación y circulación de personas, entre los cuales se encuentran los espacios peatonales, hitos, nodos y modos de transporte, etc. que generan, con la movilidad peatonal, espacios de agrupación y lugares de conexión.

Uno de los conceptos tratados en este documento es el proyecto de ciudad accesible, representado, para la investigación, en diferentes zonas de intervención peatonal generadas por las características del lugar como referentes urbanos que se articulan a lo largo de la carrera 17 de dos localidades: Teusaquillo y Barrios Unidos, en la ciudad de Bogotá.

Es muy complejo encontrar una definición que abarque todo el concepto de ciudad accesible, pues erróneamente se ha pensado que ésta solamente aplica para personas en condición de discapacidad. No obstante, la ciudad accesible abarca mucho más; debe incluir la movilidad de todos, contemplar los criterios de accesibilidad de forma transversal en todas las disciplinas. Como lo señala Corbalán (2014):
No es fácil definir lo que es una ciudad accesible, porque la accesibilidad toca numerosas disciplinas que hacen muy difícil redactar una definición empleando palabras. Sin embargo, síque podemos decir que una ciudad accesible se puede detectar por la experiencia de cualquier ciudadano en su día a día dentro de una ciudad. Cuanta mejor sea la experiencia, mayor será el grado de accesibilidad que la ciudad ofrece y no sólo por personas con discapacidad, aquí entramos todos en el mismo saco (p. 1).

Comúnmente se piensa que la solución es únicamente la implementación de rampas o vados, sin embargo, debe ser mucho más que el diseño del andén; por lo tanto, es importante tener clara la definición de ciudad accesible para todos. Como parte fundamental de este componente y de acuerdo con la Ley 1618 (art. 14, p. 13, 2013), cada una de las zonas que se contemplen como espacios públicos dentro de un proyecto, tales como andenes, vados y cruces peatonales a nivel, deberán cumplir con los parámetros establecidos en las normas técnicas y manuales de accesibilidad, movilidad reducida y decretos distritales.

AlejandraForlán(Fundación Alejandra Forlán, 2012), fundadora, psicóloga, conferencista y activista uruguaya, habló en una entrevista para el diario El Observador: 
'[...] ojalá algún día haya más trabajo para las personas con alguna discapacidad. También se podría mejorar la ciudad. Hay muchas veredas rotas, faltan rampas $y$, entre otras cosas, nos es difícil ir al supermercado porque no podemos pasar por las cajas a pagar. Faltan taxis accesibles y ómnibus de todas las líneas para nosotros'. Para Forlán lo importante es generar empatía: '[...] La mejor manera de entender la falta de accesibilidad es ponerse en el lugar de quien tiene una discapacidad' (p. 1).

Este proyecto pretende analizar la accesibilidad en las localidades de Teusaquillo y Barrios Unidos de la ciudad de BogotáColombia, teniendoen cuentalos parámetros establecidos en las Fichas de accesibilidad y la Cartilla de andenes (Alcaldía de Bogotá. Instituto de Desarrollo Urbano y Secretaría Distrital de Planeación, 2015) para evaluar si cumplen con las normativas de accesibilidad. La zona seleccionada para este estudio se ubica en la carrera 17 entre las calle 57 y 67, donde se analizan: andenes, rampas, vados, cruces peatonales, intersecciones viales, accesos al transporte público, mobiliario urbano, zonas verdes y señalización. Adicionalmente, se espera hacer un llamado de atención a quienes intervienen en las decisiones relacionadas con la accesibilidad a los entornos, edificios, servicios y productos, recogiendo las deficiencias encontradas, proponiendo una transformación que permita que se haga efectivo el derecho a la igualdad de oportunidades de las personas con discapacidad en la ciudad.
Una ciudad que no cumpla con las normas de accesibilidad, es una ciudad que carece de continuidad en sus pasos peatonales, lo que genera problemas de andenes y discriminación de los ciudadanos. Diferentes arquitectos se han dedicado a trabajar en proyectos urbanísticos como lo es Enrique Rovira, profesor de la Universidad Internacional de Cataluña, quien ha trabajado en dichos proyectos, particularmente en ciudades de España, basándose en el diseño universal. Rovira (2003) explica que la ciudad que se piensa universalmente, es una ciudad que les da espacios a todos, sus calles, sus andenes y a los materiales.

Con el propósito de seleccionar los elementos que permitan avanzar en la comprensión de la investigación, se retoman de forma global los ejes principales: accesibilidad en la movilidad peatonal; movilidad y exclusión social; y movilidad y el derecho de la ciudad. Se contempla inicialmente el concepto de movilidad peatonal y su incidencia en la consolidación de ciudades, de la misma forma, se exponen los actores y variables a considerar en la intersecciones viales. A continuación, se exponen las principales características de la exclusión social y la relación que tiene esta con la movilidad peatonal. De manera seguida, se presentan las principales características y elementos del concepto de accesibilidad peatonal. 


\section{Accesibilidad en la movilidad peatonal}

Comprender la accesibilidad como la facilidad en el desplazamiento de los peatones sin o con discapacidad para acceder o interactuar en un espacio público, andenes, cruces peatones y espacio peatonal en términos prácticos implica que los peatones logren llegar, ingresar, andar, salir, habitar, circular, ir, venir, caminar y pasar de los espacios de origen a su destino.

\section{Ley de universalidad}

El diseño universal aplicado a la movilidad peatonal tiene por objetivo principal la vida del peatón en la ciudad. El diseño universal debe ayudar a todas las personas con discapacidad ofreciéndoles un margen de seguridad en el espacio peatonal, no sólo a través de la instalación de rampas o borlados, sino generando un conjunto de elementos de espacio público y mobiliario urbano que propicien que el entorno sea accesible y positivo para mejorar la calidad de vida.

A continuación, se acoge la versión 2.0 del Centro para el Diseño Universal (Connell, Jones, Mace, Mueller, Mullick, Ostroff, Sanford, Steinfeld, Story y Vanderheiden, 1997) sobre diseño universal y se adaptan los siete principios aplicados a la movilidad peatonal:
El primer principio: uso equitativo: el diseño es útil y comerciable a personas con discapacidad; el segundo principio: flexibilidad en el uso: el diseño debe acomodar a un amplio rango de preferencias y habilidades individuales; el tercer principio: sencillo o intuitivo: el espacio debe ser fácil de entender, atendiendo a la experiencia, conocimientos, habilidades lingüísticas o grado de concentración actual del usuario; el cuarto principio: información perceptible; el quinto principio: con tolerancia al error; el sexto principio: exija poco esfuerzo físico; y el séptimo principio: tamaño y espacio para el acceso y uso.

\section{Movilidad y exclusión social}

La exclusión social y la inclusión social no deben ser iguales ni perfectos, ni la inclusión social debe ser vista como la única solución a la exclusión social (Cañón, 2010). La exclusión social puede ser definida como: la situación que se produce como consecuencia de una o varias acciones llevadas a cabo por una sociedad en la cual un miembro de ésta se ve separado de su conjunto o de alguno de sus procesos más importantes. A pesar de tal discriminación y separación que sufren los afectados por la exclusión social, se les considera parte de la sociedad. Según los siguientes autores, la exclusión social es entendida de diferentes formas. La unión Europea, por su parte, define la exclusión como "la 
imposibilidad de gozar de los derechos sociales sin ayuda, en la imagen desvalorizada de sí mismo y de la capacidad personal de hacer frente a las obligaciones propias, en el riesgo de verse relegado de forma duradera al estatus de persona asistida y en la estigmatización que todo ello conlleva para las personas y, en las ciudades para los barrios donde residen" (Comisión de las Comunidades Europeas, 1992, p. 9). Por otro lado, para Townsend, esta es entendida como un fenómeno social, concreto y específico en el cual se incluye, no sólo el hecho de padecer una privación económica de forma duradera, sino también, la no participación en la ciudad (Townsend, 1979, p. 61).

\section{Movilidad y el Derecho de la ciudad}

¿Qué es el derecho a la movilidad? La Carta del derecho a la ciudad de las Naciones Unidas y otros organismos, en el artículo 13, sobre el Derecho al transporte público y la movilidad urbana, señala que es importante

garantizar en las ciudades a todas las personas el derecho de movilidad y circulación en la ciudad, de acuerdo a un plan de desplazamiento urbano e interurbano y a través de un sistema de transporte público accesible, a precio razonable y adecuado a las diferentes necesidades ambientales y sociales (genero, edad y discapacidad) (Zetina, 2013, p. 100).

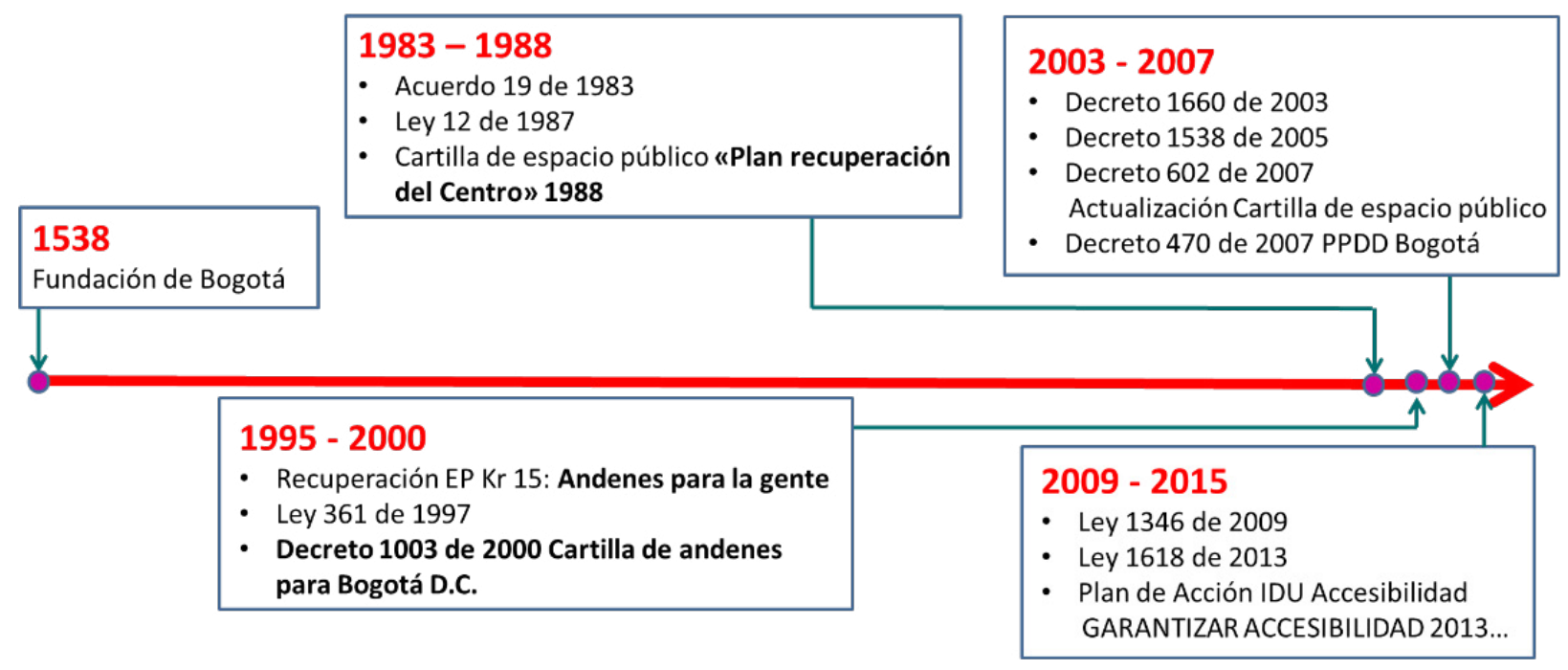

Fig. 1. Normativa Nacional de Discapacidad y Accesibilidad en la historia de Bogotá. 


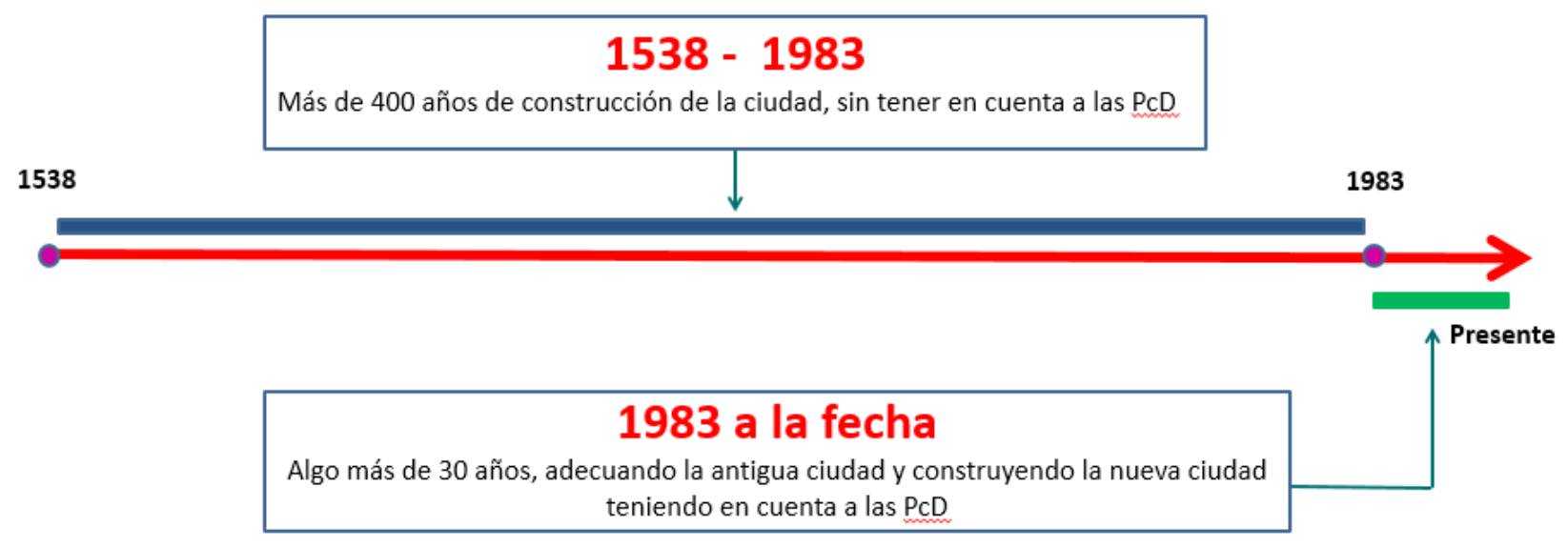

Fig. 2. Accesibilidad en la historia de Bogotá, D.C.

Fuente: elaboración propia.

El documento sobre el derecho a la ciudad demarcó la lista de derechos ciudadanos: derechos a la identidad colectiva dentro de la ciudad; a la movilidad y a la accesibilidad; a la centralidad (Borja, 2003). Desde esta perspectiva, se identifica una población con discapacidad para centrarse en la diversidad, se genera el derecho a la diferencia individual en cuanto a cultura, lengua, capacidad, genero, edad, dimensiones y mucho más. Hay muchas diferencias entre discapacidad y accesibilidad.

\section{Accesibilidad en la historia de Bogotá y localidades de Teusaquillo y Barrios Unidos}

En la ciudad de Bogotá hay diferentes localidades como Barrios Unidos, que es la localidad número 12 de la ciudad, ubicada en el noroccidente de la ciudad y limita al occidente con la calle 63; la cual la separa de la localidad de Teusaquillo, que, a su vez, la separa de la localidad de Chapinero con un terreno relativamente plano que forma parte de la sabana de Bogotá. Barrios Unidos cuenta con una gran oferta de bienes y servicios en zonas y barrios. 


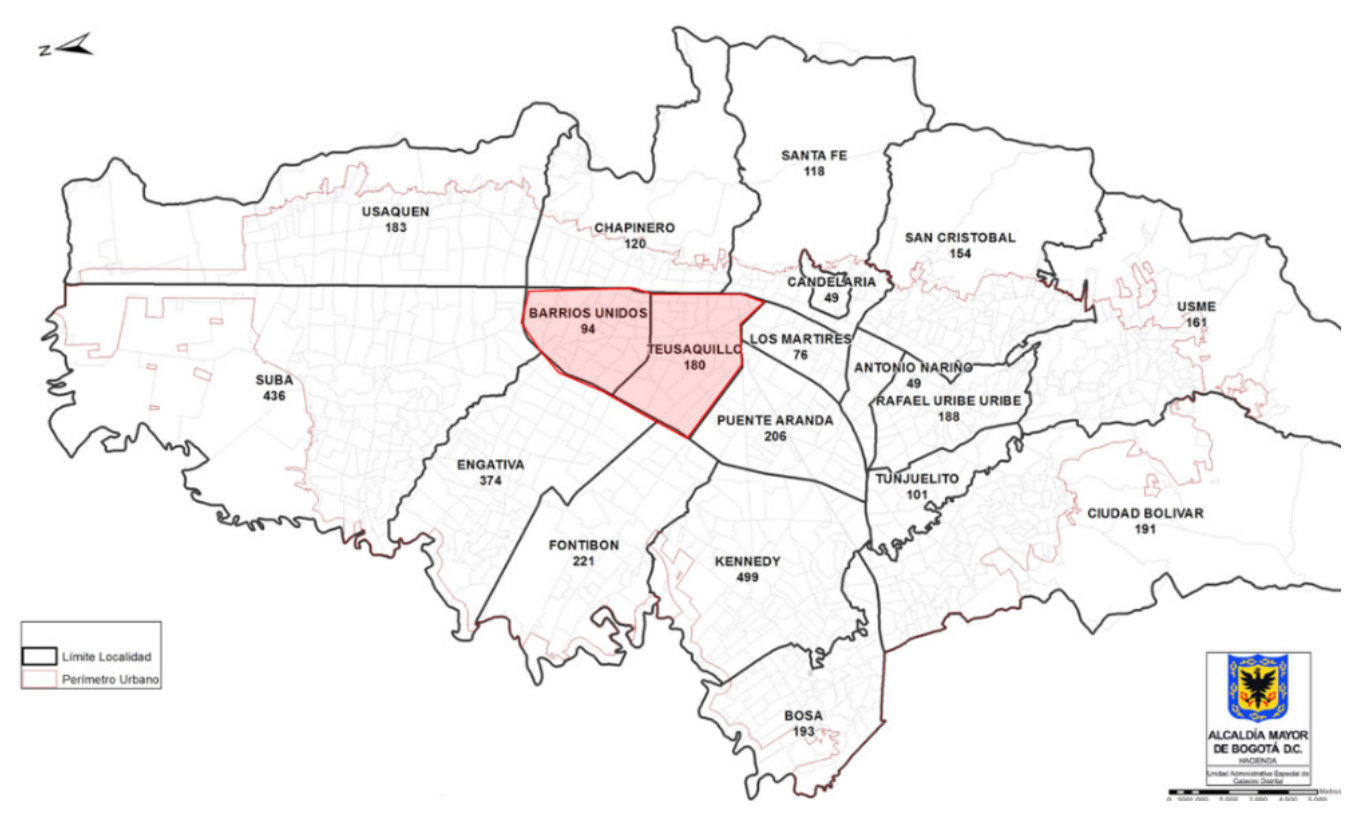

Fig. 3. Mapa de Bogotá con localidades.

Fuente: Alcaldía Mayor de Bogotá, D.C.

Por su parte, Teusaquillo es la localidad número 13 de Bogotá. Se ubica en el centro geográfico de la ciudad y limita al occidente con la localidad de Chapinero. Está ubicada al lado de la localidad de Barrios Unidos. Este es un territorio completamente urbanizado, pero que aún cuenta con muchas zonas verdes, además de zonas de comercio, educativas, de salud y administrativas.

Durante el siglo XXI, estas localidades han sido objeto de remodelación como resultado de la llegada del sistema masivo de transporte Transmilenio a la avenida
Caracas y a la avenida carrera 30. En consecuencia, han sido sometidas al mejoramiento de sus calles, andenes y espacios públicos en general. Las más importantes vías de Teusaquillo y Barrios Unidos son la calle 63, la calle 53, la carrera 24, la carrera 17, la avenida Caracas y la avenida Carrera 30; en sus principales vías cuentan con rutas de servicio público de buses, busetas, colectivos y Transmilenio, a las que llegan los peatones sin o con discapacidad en todos los barrios de las dos localidades y la comunican con toda la ciudad (Figs. 3 y 4 ). 


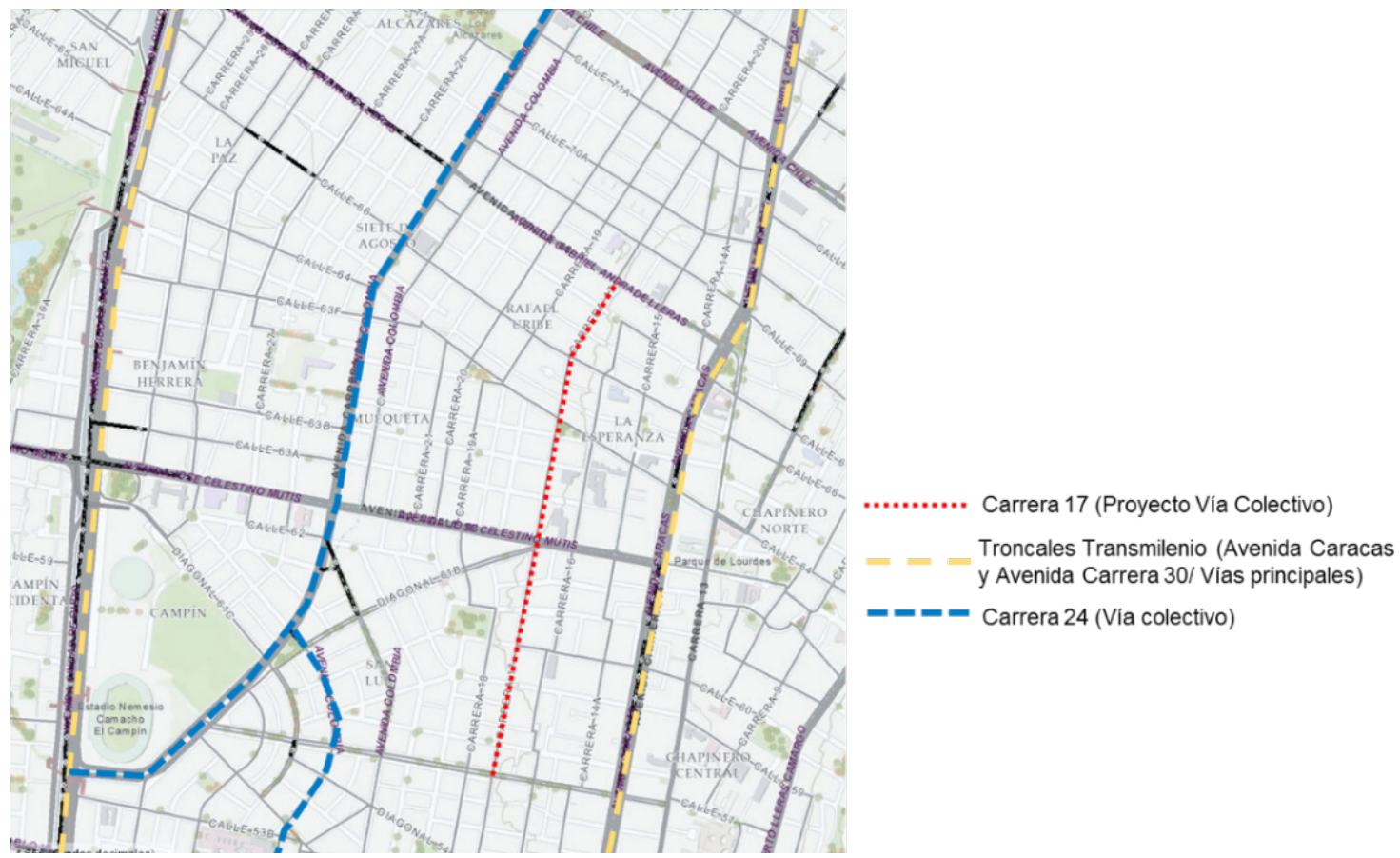

Fig. 4. La zona entre dos localidades: Barrios unidos y Teusaquillo.

Fuente: elaboración propia.

\section{Los marcos internacionales y nacionales de discapacidad y accesibilidad}

Hay que apreciar las disposiciones internacionales a lo largo del tiempo. La Declaración Universal de los Derechos Humanos se aprobó en 1948, pero hoy en día muchas personas no pueden ejercer sus derechos en igualdad de condiciones, ni son tratadas de forma plenamente equitativa en nuestra sociedad, como es el caso de las personas con discapacidad intelectual. Teniendo en cuenta la Declaración de los Derechos de las Personas con Discapacidad, proclamada por la Asamblea General de la Organización de las Naciones Unidas-ONU el 9 de diciembre de 1975, es crucial no olvidar que en su artículo 3 dice: "la persona discapacitada tiene derecho a que se respete su dignidad humana y a disfrutar de una vida decorosa, lo más normal y plena que sea posible, cualquiera que sea el origen, la naturaleza o la gravedad de sus trastornos y deficiencias" (ONU, 1975, p. 93). 
En el año 1992 fue aprobada la Declaración de Cartagena sobre políticas integrales para las personas con discapacidad en el área Iberoamericana. Uno de los principales resultados del Decenio de las Naciones Unidas para los Impedidos fue la aprobación, por la Asamblea General, el 20 de diciembre de 1993, de las Normas uniformes sobre la igualdad de oportunidades para las personas con discapacidad:

Aunque no se trata de un instrumento jurídicamente vinculante, las Normas Uniformes representan el firme compromiso moral y político de los gobiernos respecto de la adopción de medidas encaminadas a lograr la igualdad de oportunidades para las personas con discapacidad. Las Normas son un instrumento para la formulación de políticas y sirven de base para la cooperación técnica y económica (ONU, 1993).

En el año 2006, las Naciones Unidas aprobaron una Convención sobre los Derechos de las Personas con Discapacidad en la cual se "establece que las personas con discapacidad tienen los mismos derechos que cualquier otra persona y que somos iguales ante la ley" (ONU, 2006).

$Y$ continuando con el contexto internacional, se encuentran:

El marco constitucional español: es un marco constitucional para la accesibilidad y no discriminación en el acceso y utilización de los espacios públicos urbanizados.

El marco normativo autonómico: Ley Foral de Navarra, 5/2010 de 6 de abril (Gobierno de Navarra, 2010), de accesibilidad universal y diseño para todas las personas.
El marco legislativo y reglamentario estatal: donde se ordenan por orden cronológico las leyes de discapacidad y accesibilidad.

Así también, en Colombia existen diferentes medidas para reglamentar estos derechos. Estas se citarán a continuación:

El artículo 82 de la Constitución Política de Colombia establece que: "es deber del Estado velar por la protección de la integridad del espacio público y su destinación al uso común" (art. 82, 1991).

El artículo 14 de la ley estatutaria 1618 (2013) sobre acceso y accesibilidad establece que:

Las entidades del orden nacional, departamental, distrital y local garantizarán el acceso de las personas con discapacidad en igualdad de condiciones, al entorno físico, al transporte, a la información y a las comunicaciones, incluidos los sistemas y tecnologías de la información y las comunicaciones, el espacio público, los bienes públicos, los lugares abiertos al público y los servicios públicos, tanto en zonas urbanas como rurales (art. 14, 2013).

Mediante el Decreto Distrital 1003 de 2000, adicionada mediante Decreto Distrital 379 de 2002, actualizada mediante los Decretos Distritales 602 de 2007 y 561 de 2015, y se dictan otras disposiciones se adoptó la Cartilla de Andenes de Bogotá, D.C. Como sistema constructivo de los mismos, se reglamentó el diseño y la construcción de andenes y espacios públicos de circulación peatonal en el Distrito Capital. 
El decreto Distrital 215 (2005), por el cual se adoptó el "plan Maestro de Espacio Público para Bogotá Distrito Capital", establece como estrategia de la política de calidad del espacio público, ampliar el ámbito de aplicación y complementar las directrices de la "Cartilla de Andenes".

Asimismo, mediante el Decreto Distrital 602 (2007):

Se actualizó la Cartilla de Andenes, adoptada mediante el Decreto Distrital 1003 de 2000, incorporando una alternativa de soluciones combinada de áreas duras y empradizas para andenes de vías locales en algunos proyectos de vivienda de interés prioritario VIP y algunos elementos para facilitar la integración al medio físico de personas con discapacidades motrices o visuales (Decreto 602, 2007).

Finalmente, se presenta lo expuesto en el Decreto 561 (2015):
Para el proceso de actualización de la Cartilla de Andenes, la Secretaría Distrital de Planeación en coordinación con las Secretarías Distritales de Ambiente, Hábitat y Movilidad, el Jardín Botánico 'José Celestino Mutis' y el Instituto de Desarrollo Urbano, identificaron los temas a revisar y desarrollaron los aspectos de Ecourbanismo, accesibilidad e inclusión al medio físico a complementar y ajustar en la 'Cartilla de Andenes' en aplicación de las políticas públicas de Discapacidad y Ecourbanismo y construcción Sostenible.

(...), en virtud de lo anterior, se hace necesario adoptar la presente actualización de la Cartilla de Andenes, incorporando, de manera integral, lineamientos técnicos de diseño y especificaciones técnicas de diseño y construcción orientados, por una parte, a garantizar el acceso a las personas con discapacidad, en igualdad de condiciones, al entorno físico y al espacio público del Distrito Capital y, por otra parte, a la implementación de prácticas sostenibles de urbanismo y construcción que contribuyan a la mitigación y adaptación de Bogotá a los efectos del cambio climático (Decreto 561, 2015).

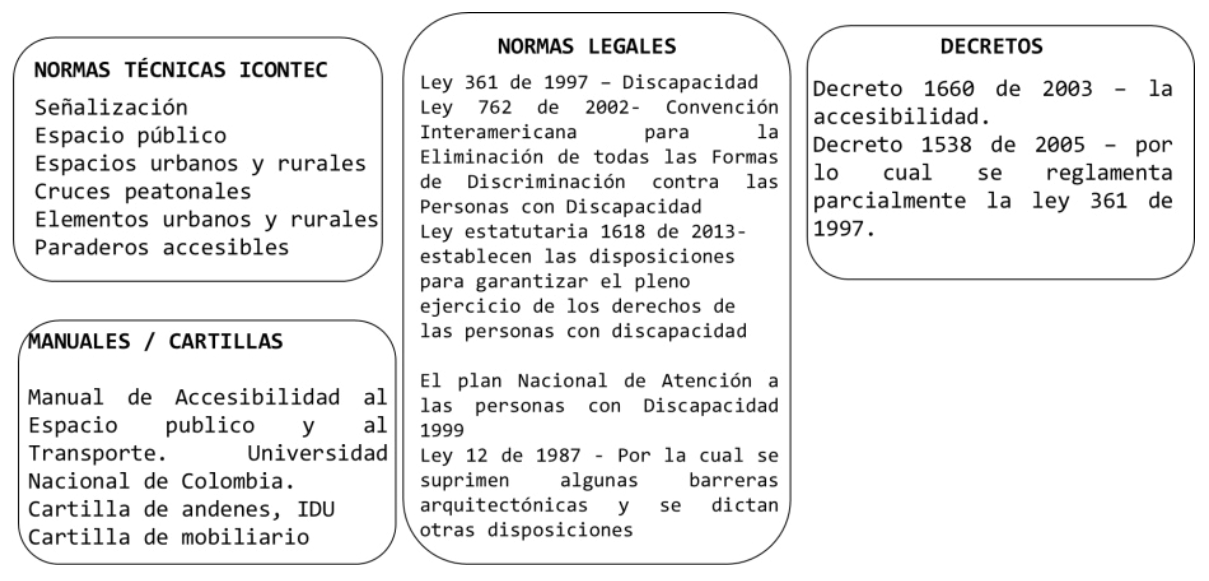

Fig. 5. Marco legal nacional.

Fuente: elaboración propia. 


\section{Metodología para el diagnóstico y mejoramiento de la accesibilidad en zonas de espacio público}

Accesibilidad. La ley estatutaria 1618 (2013), define accesibilidad como las

condiciones y medidas pertinentes que deben cumplir las instalaciones y los servicios de información para adaptar el entorno, productos y servicios, asícomo los objetos, herramientas y utensilios, con el fin de asegurar el acceso de las personas con discapacidad, en igualdad de condiciones, al entorno físico, el transporte, la información y las comunicaciones, incluidos los sistemas y las tecnologías de la información y las comunicaciones, tanto en zonas urbanas como rurales. Las ayudas técnicas se harán con tecnología apropiada teniendo en cuenta estatura, tamaño, peso y necesidad de la persona.
Descripción y análisis del problema. El espacio público es un lugar de uso y acceso para todas las personas sin ninguna distinción física, racial, social, económica o política, quienes, a su vez, tienen derecho al mismo. Pero, ¿cómo hacer para que el espacio público sea un lugar de uso colectivo en el que no se discrimine a ningún ciudadano o ciudadana, en especial a las personas con discapacidad?

En respuesta a lo anterior, y desde la perspectiva del diseño, construcción, mantenimiento y conservación de estos lugares, es necesario que el mismo se conciba de tal manera que su forma y función no transgreda o violente los derechos de los ciudadanos, en especial los de aquellos o aquellas que se encuentran en condiciones vulnerables y/o de discapacidad. En síntesis, es necesario que el espacio público sea accesible e incluyente.

Tabla 1

Componentes objeto de análisis.

\begin{tabular}{|c|c|c|}
\hline $\begin{array}{l}\text { Código } \\
\text { componente }\end{array}$ & Componente & Descripción \\
\hline 1 & Andén & $\begin{array}{l}\text { Franja paralela a una vía vehicular destinada al tránsito de peatones, ubicación } \\
\text { de mobiliario urbano y redes de servicio público, entre otros. }\end{array}$ \\
\hline 2 & Vado & $\begin{array}{l}\text { Es una modificación en el andén que consiste en rebajar el sardinel para salar el } \\
\text { desnivel existente entre la acera y la calzada. }\end{array}$ \\
\hline 3 & $\begin{array}{l}\text { Sendero } \\
\text { peatonal }\end{array}$ & $\begin{array}{l}\text { En el recorrido longitudinal que existe en cualquier tipo de superficie destinada al } \\
\text { tránsito de peatones. }\end{array}$ \\
\hline 4 & $\begin{array}{l}\text { Esquina de } \\
\text { andén }\end{array}$ & $\begin{array}{l}\text { Es la parte final del sendero peatonal de un andén y se encuentra siempre en las } \\
\text { bocacalles (desembocadura de una vía en otra de igual o mayor flujo vehicular). }\end{array}$ \\
\hline 5 & $\begin{array}{c}\text { Cruce } \\
\text { peatonal }\end{array}$ & Es el paso permitido a las personas a través de una vía vehicular \\
\hline
\end{tabular}


Tabla 2

Fallas de accesibilidad por componente objeto de análisis

\begin{tabular}{|c|c|c|c|}
\hline Componente & $\begin{array}{l}\text { Código } \\
\text { falla }\end{array}$ & Falla accesibilidad & $\begin{array}{l}\text { NTC de } \\
\text { referencia }\end{array}$ \\
\hline \multirow{7}{*}{ Andén } & 1.1 & Ancho del andén inferior al mínimo permitido & 4279 \\
\hline & 1.2 & $\begin{array}{l}\text { Andén sin continuidad en su recorrido peatonal, por cambios de nivel } \\
\text { en el mismo }\end{array}$ & $4270-4143$ \\
\hline & 1.3 & Andén con pendiente transversal superior al máximo permitido & 4143 \\
\hline & 1.4 & Andén con pendiente longitudinal, superior al máximo permitido & 4143 \\
\hline & 1.5 & Andén sin señalética de piso para invidentes & 5610 \\
\hline & 1.6 & Andén con señalética de piso para invidentes mal instalada & 5610 \\
\hline & 1.7 & $\begin{array}{l}\text { Andén sin continuidad en su recorrido peatonal por la presencia de } \\
\text { obstáculos o barreras físicas }\end{array}$ & 4279 \\
\hline \multirow{4}{*}{ Vado } & 2.1 & Ancho vado menor al mínimo permitido & 4143 \\
\hline & 2.2 & Porcentaje de pendiente vado mayor al máximo permitido & 4143 \\
\hline & 2.3 & Vado sin señalética de piso para invidentes & $4143-5610$ \\
\hline & 2.4 & Remate rampa vado con respecto a calzada, diferente a 0,0 & 4143 \\
\hline \multirow{7}{*}{$\begin{array}{l}\text { Sendero } \\
\text { peatonal }\end{array}$} & 3.1 & Ancho del sendero inferior al mínimo permitido & 4279 \\
\hline & 3.2 & $\begin{array}{l}\text { Sendero sin continuidad en su recorrido peatonal, por cambios de nivel } \\
\text { en el mismo }\end{array}$ & 4143 \\
\hline & 3.3 & Sendero sin señalética de piso para invidentes & 5610 \\
\hline & 3.4 & Sendero con señalética de para invidentes, mal instalada & 5610 \\
\hline & 3.5 & Sendero con pendiente transversal, superior al máximo permitido & 4143 \\
\hline & 3.6 & Sendero con pendiente longitudinal, superior al máximo permitido & 4143 \\
\hline & 3.7 & $\begin{array}{l}\text { Sendero sin continuidad en su recorrido peatonal por la presencia de } \\
\text { obstáculos o barreras físicas }\end{array}$ & 4279 \\
\hline \multirow{3}{*}{$\begin{array}{l}\text { Esquina } \\
\text { andén }\end{array}$} & 4.1 & Esquina de andén sin acceso * & 4143 \\
\hline & 4.2 & Esquina de andén sin señalética de piso para invidentes & 5610 \\
\hline & 4.3 & Esquina de andén con barreras físicas & $\mathrm{NE}$ \\
\hline \multirow{5}{*}{$\begin{array}{c}\text { Cruce } \\
\text { peatonal }\end{array}$} & 5.1 & Cruce peatonal sin vados & 4143 \\
\hline & 5.2 & Cruce peatonal sin alineación en los vados & 4143 \\
\hline & 5.3 & Separador vial cruce peatonal, no accesible & NE \\
\hline & 5.4 & $\begin{array}{l}\text { Cruce peatonal sin garantía, por estar sobre una vía destapada o a } \\
\text { riesgo }\end{array}$ & NE \\
\hline & 5.5 & Cruce peatonal sobre vía férrea, no accesible & NE \\
\hline
\end{tabular}

* Aplica para esquinas de andén en vías locales o con cruce peatonal autorizado por la Secretaría de Movilidad NE; No Existe

Fuente: elaboración propia. 
Fase 1: Diagnóstico. Esta fase consiste en un recorrido de campo por los corredores que son objeto de intervención a fin de evaluar su estado con respecto a las normas y manuales de accesibilidad anteriormente descritas (ver el marco normativo). En el desarrollo de esta fase se realiza la toma de datos en terreno. En esta actividad, se efectúan las siguientes tareas:

Identificación de fallas de accesibilidad en los corredores. Se realiza una inspección a los componentes que influyen en el tránsito peatonal con el fin de determinar las fallas que presentan en materia de accesibilidad. La inspección se puede guiar con las NTC descritas en el Marco normativo. Así, los componentes que se analizan, se describen en la tabla 1; y las fallas de accesibilidad que se pueden detectar a nivel general en el terreno, se detallan en la tabla 2.

Registro fotográfico de las fallas de accesibilidad. Una vez detectada la falla de accesibilidad, se toman las fotografías necesarias para su detalle.
Categoría de discapacidad. Se hace una identificación de la discapacidad relacionada con la falla, como por ejemplo, una barrera física, que es cualquier tipo de obstáculo que dificulta y, en muchos casos, imposibilita la circulación peatonal, especialmente, la circulación de personas con discapacidad y movilidad reducida.

Toma de dimensiones básicas. Según el componente y la falla detallada en las fotografías, se procede a tomar sus dimensiones básicas. Las dimensiones básicas que se toman en el terreno son: ancho del andén, anchos esquina andén, ancho - recorrido y pendiente de los vados, junto con las demás dimensiones que estimen los técnicos de accesibilidad que sean específicas del terreno y que se deseen detallar en el diagnóstico.

Procedimiento para la toma de datos en terreno. Para recopilar la información descrita, se utiliza el formato que se describe en la tabla 3.

Tabla 3

Facsímil del formato para la toma de datos en terreno.

\begin{tabular}{|c|c|c|c|c|c|}
\hline Tramo & Localidad _ & Fecha & Elaboró & Hoja & de \\
\hline \multirow{2}{*}{$\begin{array}{r}\text { Dirección } \\
\text { costado }\end{array}$} & \multicolumn{2}{|c|}{ Registro fotográficco } & \multirow{2}{*}{$\begin{array}{c}\text { código componente } \\
\text { analizado }\end{array}$} & \multirow{2}{*}{ Dimensiones } & \multirow{2}{*}{$\begin{array}{l}\text { Código Falla de } \\
\text { acceisibilidad }\end{array}$} \\
\hline & de la & a la & & & \\
\hline & & & & & \\
\hline & & & & & \\
\hline
\end{tabular}


Instrucciones para el diligenciamiento del formato para la toma de datos en terreno: La información que se debe diligenciar en el encabezado del formato es la siguiente:

Tramo analizado: en este campo se debe escribir el mismo nombre, número o código que se utilizó para nombrar el corredor dentro de la priorización.

Localidad: en este campo se debe escribir el nombre de la localidad a la que pertenece el eje.

Fecha: en este campo se diligencia la fecha cuando se toman los datos.

Elaboró: en este campo se escriben los nombres de los técnicos que recopilan la información.

Hoja__de__: en este campo se escribe el número de la hoja tramitada con respecto al total de hojas que salen durante el diagnóstico por tramo.

Nota: el número de hojas refieren a las necesarias para analizar el tramo y no al total de las realizadas en una jornada de trabajo.

La información que se debe diligenciar en el cuerpo del formato es la siguiente:

Dirección - costado: en este campo se escribe la dirección y el costado del componente donde se detecta la falencia.

Registro fotográfico - de la, a la: en este campo se escribe el número de serie (según la carpeta donde se guardan los archivos) de las fotos que se toman del componente para el detalle de la falencia. Ejemplo: de la 10 a la 20.

Código del componente analizado: en este campo se escribe el código del componente donde se detecta la falencia (tabla 3).
Dimensiones: en este campo se escriben las dimensiones básicas tomadas en terreno del componente donde se detecta la falencia.

Código de la falla de accesibilidad: en este campo se escribe el código de la falla que se detalla para el componente (tabla 3).

Fase 2: Elaboración del documento técnico de soporte. En esta actividad se realizan las siguientes tareas:

Formulación de las recomendaciones de accesibilidad. Para esta tarea se diseñaron un total de 12 fichas de accesibilidad y se utilizó la Cartilla de Andenes del Instituto de Desarrollo Urbano. Específicamente, las fichas contienen esquemas de andenes, vados, esquinas de andén, cruces peatonales y rampas para senderos peatonales con indicaciones y/o recomendaciones generales basadas en el marco normativo NTC expuesto. La información consignada en las fichas esta relacionada en la tabla 4.

\section{Recomendaciones de la comunidad (Participación de las PcD en el Diseño - Codiseño)}

Con el fin de acompañar a nivel social la intervención en el espacio púbico en el segmento priorizado, se propone a los gestores de la Secretaría Técnica de Discapacidad, como en los Consejos Locales de Discapacidad, diseñar e implementar herramientas sociales que logren complementar los cabildos ciudadanos realizados previamente con talleres de imaginarios 
Tabla 4

Contenido fichas de accesibilidad

No. Contenido NTC de

1 En esta ficha se consignan los lineamientos generale para la utilización de la señalética de piso para invidentes y la pendiente transversal de un sendero peatonal

En esta ficha se consignan los lineamientos generales para un vado. Es de anotar

2 que la NTC 41343 sugiere un ancho mínimo de $0.9 \mathrm{~m}$. En esta ficha se sugiere un ancho mínimo de $2.0 \mathrm{~m}$. y el máximo de acuerdo al ancho de la zona de circulación peatonal

5610

En esta ficha se consignan los lineamientos generales de accesibilidad para una

3 esquina estándar de andén. Una esquina estándar se ubica en andenes que van de $2.8 \mathrm{~m}$. en adelante

En esta ficha se consigna los lineamientos generales de accesibilidad para una

4 esquina deprimida. Llamada así, porque su borde externo es rebajado hasta el nivel de la calzada. Se utilizan en andenes de alto flujo peatonal y con anchos superiores a los $3.2 \mathrm{~m}$.

En esta ficha se consignan los lineamientos generales para la esquina de andén 5 angosto, Un andén angosto va desde los $1.2 \mathrm{~m}$. hasta los $2.8 \mathrm{~m}$. En esta clase de esquina, su borde externo es rebajado hasta el nivel de la calzada, debido a que sus dimensiones no permiten la construcción de un vado de acuerdo a las normas.

6 En esta ficha se consignan los lineamientos para salvar un cambio de nivel en el andén y así brindar continuidad en su recorrido peatonal

4279

5610

7 En esta ficha se consignan los lineamientos generales para un separador vial

8 En esta ficha se consignan los lineamientos generales para un cruce peatonal estándar. Estos cruces son típicos en vías intermedias y locales

En esta ficha se consignan los lineamientos generales para un cruce peatonal con

9 separados vial. Aunque la normal NTC 4143, menciona la necesidad de alinear los vados en un cruce peatonal, no existe una norma específica NTC que indique un cruce con separador

En esta ficha se consignan los lineamientos generales para una rampza escalonada, recomendada para senderos peatonales con una pendiente longitudinal superior al

$1012 \%$. Ejemplo, senderos peatonales en zonas de montaña, parques con loma, subidas con pendientes pronunciadas, etc.

11 En esta ficha se consignan los lineamientos generales para garantizar, diferenciar y resaltar un cruce peatonal, en una vía en mal estado o un cruce a riesgo

12 En esta ficha se consignan los lineamientos generales para cruce peatonal sobre una línea férrea 
sociales (Empresa de Desarrollo UrbanoEDU, 2018), los cuales tendrán la finalidad de facilitar procesos comunitarios para la generación de lineamientos de diseño y apropiación del espacio público según las necesidades y expectativas de la comunidad.

Contemplar los imaginarios sociales como fundamentales en estos procesos comunitarios hacia el urbanismo, les permite a los sujetos de una sociedad que se identifiquen y se sientan parte fundamental del escenario en donde convergen con otros actores. Estos atributos identitarios que se complementan con el legado histórico de cada contexto, facilitan en los sujetos una autodeterminación y prácticas de cooperativismo que les permite distinguirse a nivel socio-territorial de otros grupos poblacionales. Por ende, debe tenerse en cuenta que "la sociedad es un conjunto de significaciones imaginarias sociales cuya vida se encarna en las instituciones capaces de transformar y de conferirle sentido a los aconteceres" (Pintos, 1995, p. 61).

Esta capacidad de transformar requiere de dos elementos fundamentales: el primero es la conformación de la psique de los individuos, quienes crean una representación del mundo, no sólo como un constructo intelectual, sino con el segundo elemento fundamental, la creación del impulso de la sociedad que se conforma por las emociones e impulsos del hombre, que, al colectivizarse, se convierten en prácticas sociales, racionales e imaginativas que ayudan a la transformación de un entorno determinado:

\begin{abstract}
[...] bajo esta dimensión se construye e instituye una manera de pensar la sociedad no tanto desde lo determinable, sino más bien de la creación indeterminada e incesante de la sociedad, de sus producciones y los significados, sentidos y prácticas que se movilizan con esas producciones (Vásquez, 2001, p. 29).
\end{abstract}

Comprender la incidencia de los imaginarios sociales en la explicación fenomenológica de la sociedad no solo contempla los dos niveles de profundización ya mencionados, sino que también permite asumir que los imaginarios son múltiples construcciones mentales construidas y colectivizadas que dan sentido a la vida, tal como se menciona a continuación:

Más allá de cierto plano de descripciones fundamentales, $y$ sobre todo ese algo no se da completamente en la superficie y en una apariencia concreta, la tarea que se asigna la actividad mental es la construcción plausible o convincente de la realidad (Baeza, 2004, p. 41).

De esta forma, se entiende que la explicación de los fenómenos sociales o de las acciones cotidianas de un entorno específico no sólo se puede exponer bajo esquemas de racionalidad objetiva y tajante, propias de la modernidad, sino que, además, permite comprender que los imaginarios, como representaciones mentales que acogen imágenes, percepciones, emociones y sentimientos de los individuos, explican en gran medida comportamientos y acciones hermenéuticas de comunidades que 
abren la posibilidad de representar simbólicamente lo que sucede. Adicionalmente, cabe aclarar que es el lugar en donde se expresan los deseos, así como insatisfacciones y expectativas, con lo cual se preservan o generan cambios sociales.

Para realizar cambios en la sociedad a través de los imaginarios sociales, se requiere de un parámetro valorativo y de dispositivos de validez donde los sujetos legitimen dichas representaciones simbólicas como explicativas e interpretativas de la realidad. El imaginario responde entonces a la necesidad de posicionamiento de los individuos en un intento por explicarse su relación y posición ante la realidad, sin que ello relegue la importancia de la imaginación como un vehículo para entender el modo en el que ha funcionado y funciona el mundo, para suplir o transformar insatisfacciones comunitarias en pro de la reconstrucción de escenarios concretos en los que se desenvuelven los sujetos sociales.

\section{Metodología de los talleres de imaginarios sociales (participación del Concejo local de discapacidad - Codiseño)}

Jornada de sensibilización. Para dar inicio a este taller, se requiere empezar con una jornada de sensibilización pedagógica en el que se proyecte a las personas de las entidades públicas de Bogotá la necesidad de reconocerse como sujetos activos de derecho y, por ende, gestores de su propio desarrollo, cuyo ejercicio participativo es fundamental para la planeación integral y objetiva de la ciudad.

Por esta razón, se proponen diferentes ayudas visuales que contribuyan con la sensibilización, y, en consecuencia, con la toma de conciencia sobre la importancia de planear conjuntamente como medio de transformación y cambio social; por lo tanto, esta ayuda pretende especificar o profundizar en los siguientes componentes:

- ¿Qué es planear?

- Ciclo de la planeación

- ¿Quiénes planean?

— ¿Qué planeamos?

- ¿Cuáles son los puntos de barreras urbanísticas?

- ¿Cuáles son los puntos de ciudad accesible para mejorar la vida e inclusión social?

Detección y comprensión de necesidades y problemas sociales del sector a intervenir. Después de haber generado un acercamiento importante con la comunidad de locales y de haber tenido la posibilidad de profundizar sobre la importancia de generar redes sociales o fortalecer tejidos sociales para la planeación participativa, se entrará a enunciar, detectar, georreferenciar y comprender las necesidades o problemáticas sociales que los mismos habitantes del sector padecen.

Enumeración. En este momento, la comunidad de manera participativa y colectiva, empieza a enumerar las problemáticas sociales que observan en los diferentes sectores que implican cada una de las áreas de intervención. 
Georreferenciación. Después de haber detectado aquellos núcleos problemáticos, se procede a georreferenciar a través una herramienta metodológica de cartografía social en la que la misma comunidad o actores cualificados para la participación elaboran un mapa de su sector y empiezan a dibujar y centralizar puntos del territorio que tienden a ser complejos por la presencia de dichas deficiencias sociales. El ejercicio de ubicar en un mapa aquellos puntos o epicentros con necesidades sociales debe estar acompañado de un mapeo de puntos o escenarios que den cuenta de sentimientos de identidad, este puede tomar como base los sectores de interés cultural relacionados con el patrimonio cultural material e inmaterial.

La cartografía social responde a este gran argumento de Paulo Freire, quien expone que:

La tierra de la gente es su geografía, ecología, su topografía y biología. Ella es tal como organizamos su producción, hacemos su historia, educación, su cultura, su comida y su gusto al cual nos acostumbramos. La tierra de las personas implica lucha por sueños diferentes a veces antagónicos como los de sus clases sociales mi tierra no es, finalmente una abstracción (Freire, 1997).

Lo interesante de esta herramienta metodológica es que permite poner en evidencia que el mapa del territorio en el que la comunidad vive es realizado por ellos mimos en su ejercicio de cooperación y trabajo colectivo, lo que facilita el intercambio de saberes y de percepciones territoriales que configuran todo un escenario y, por ende, lo ordenan según las dinámicas socioculturales que se inscriben en dicho espacio.

Por lo tanto, es una construcción con un lenguaje propio en el que la simbología es fundamental a la hora de representar aquellos epicentros problemáticos o de conservación de patrimonio cultural, pues, más allá de homogenizar ciertos caracteres, es la posibilidad para redescubrir otra forma de representarlos, y, por ende, ubicarlos:

Es un ejercicio colectivo de reconocimiento del entorno socio-territorial a través de la construcción de mapas; con este ejercicio se evidencian las relaciones sociales, se develan saberes que permite a sus participantes un mejor conocimiento de su realidad, genera espacios de reflexión y permite construir un lenguaje común de interpretación de las diferentes percepciones de la realidad presente en las comunidades (Molina, 2005, p. 01).

Para poder llevar a cabo la cartografía social, es necesario precisar algunos instrumentos que se consideran fundamentales para dicha herramienta metodológica: los mapas, planos y elementos volumétricos para acercarse a la representación de alturas, densidades y localizaciones de las estructuras del sector; observación participante; y encuesta de percepción e ideas (post it).

Instrumentos vivenciales. Desarrollar talleres, trabajo en equipo, recorridos de campo, narración de experiencias cotidianas, plenarias, creación simbólica, material visual, entrevistas, videos y fotos. 
Visualización de expectativas sobre la transformación del sector a partir de preguntas detonadoras

- ¿Qué ventajas y desventajas tiene estar en el sector?

- ¿Qué ventajas y desventajas tendría que hicieran cambios en el sector?

- ¿Cuál es el lugar más seguro del sector y por qué?

- ¿Cuál es el lugar más peligroso del sector y por qué?

- ¿Cuál es el color que identifica tu sector y por qué?

- ¿Cuál es la figura de poder que más ha influido en la realidad del sector?

- ¿Con qué sentimiento le gustaría que fuera identificado su sector?

- ¿Considera que permanecer en este territorio le genera beneficios económicos?

- ¿Qué se ha ganado y perdido en los últimos 5 años? (Universidad de los Andes, 2012a)

Cada una de las preguntas comprende categorías de análisis como: permanencia, ubicación, sostenibilidad (ambiental, equipamientos, servicios, económia y religión), seguridad, movilidad, y otros.

Esta visualización permite a los participantes de la comunidad retomar la memoria histórica y legado del sector para asumir una postura de pertenencia al territorio, al recordar, manifestar inquietudes, temores e inconformidades hacia el mismo. Esta acción permite un avance significativo en los procesos participativos, pues centra la proposición y comprensión en las dinámicas territoriales que ordenan el sector.
Reflexiones sobre el territorio. Para este proyecto, se requiere trabajar bajo dos supuestos planteados previamente por Armando Silva (2006) en su texto "Imaginarios Urbanos":

- Ciudad vista. Entendida como aquella instancia que tiene en cuenta los diferentes puntos de vista de los ciudadanos frente a la ciudad (lectura colectiva de la misma); esta instancia de leer a la ciudad no sólo implica el conocimiento y la georreferenciación de lugares específicos, sino acoger la interpretación, la narración y los escritos que la población realiza de su territorio o ciudad.

- Ciudadimaginada. Laforma de imaginar la ciudad está articulada con la imaginación simbólica que se da cuando el significado "[...] no se podrá presentar con una cosa específica, en cuanto tal, una palabra exacta o una descripción única, y lo que presenta es más que una cosa, un sentido o muchos que pueden abarcar la expresión simbólica" (Silva, 2006, p. 91). Por tal, la ciudad imaginada es una ciudad que cumple con el anhelo de las niñas y los niños, los jóvenes y los ciudadanos frente a su territorio, un lugar donde se interpreten sus representaciones de ciudad y, por ende, sus intenciones sociales.

Estas intenciones sociales se articularán con los elementos establecidos en los Principios de desarrollo urbano para el transporte en la vida urbana, los cuales son: caminar, pedalear, conectar, transitar, combinar, densificar, compactar y cambiar (ITDP, 2017), como una propuesta urbanística integral e incluyente (Fig. 6). 

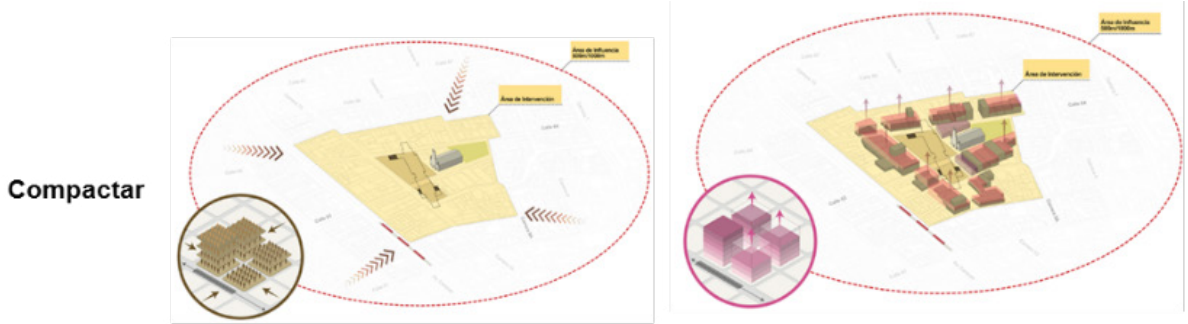

Densificar
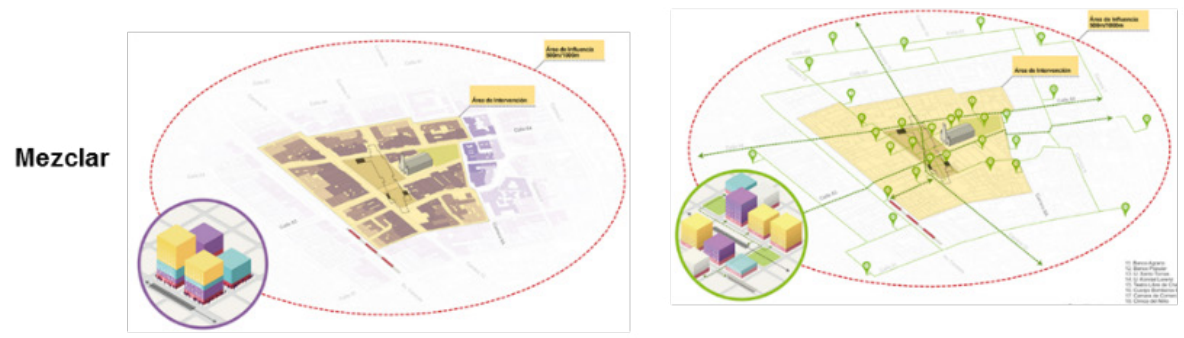

\section{Conectar}
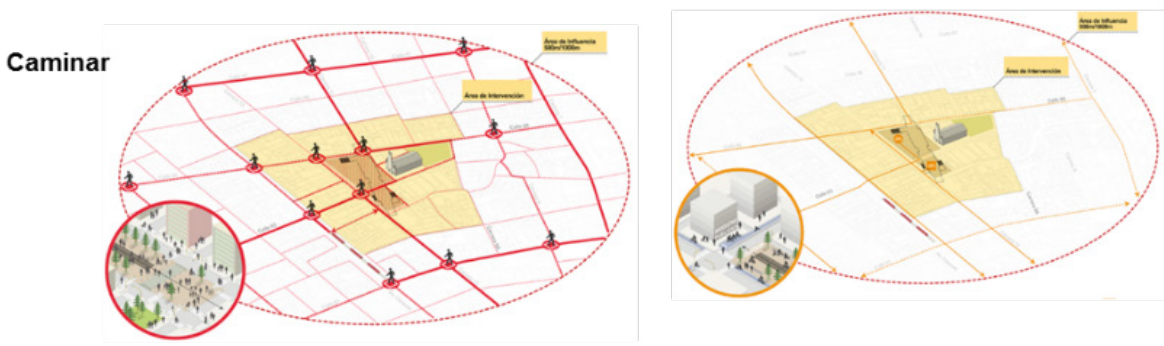

Pedalear

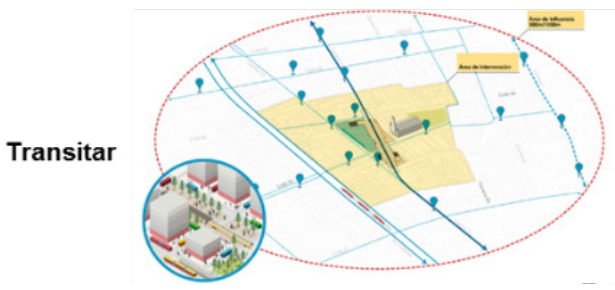

Fig. 6. Eelementos y principios del desarrollo urbano para el transporte en la vida urbana. Fuente: elaboración propia a partir de ITDP, 2017.

Teniendo en cuenta lo anterior, es necesario que, en el taller, el grupo se divida en subgrupos para que, posteriormente, se entregue a cada uno de ellos 2 planos (uno con el sector actual y otro sin edificaciones), marcadores, papeles de colores, bloques de madera y tijeras. 
Tabla

Actividades a realizar con los dos planos en el taller.

\begin{tabular}{ll}
\hline \multicolumn{1}{c}{ Primer plano (ciudad vista) } & \multicolumn{1}{c}{ Segundo plano (cuidad imaginada) } \\
\hline $\begin{array}{l}\text { En esta, se georreferenciarán los núcleos } \\
\text { problemáticos (PUI) que se observaron } \\
\text { anteriormente. }\end{array}$ & $\begin{array}{l}\text { Se plantea la posibilidad de especificar qué cosas } \\
\text { se desea que se conserven (flujos de circulación y } \\
\text { localización de actividades). }\end{array}$ \\
\hline & $\begin{array}{l}\text { A partir de los flujos identificados, se indaga sobre la } \\
\text { posible localización de las actividades que existen y otras }\end{array}$ \\
$\begin{array}{l}\text { Se pone en evidencia lo que hay } \\
\text { actualmente (flujos de circulación y } \\
\text { localización de actividades). }\end{array}$ & $\begin{array}{l}\text { que desea que existan. Los elementos se identificarán } \\
\text { con loubos o figuras representativos de las actividades, }\end{array}$ \\
& $\begin{array}{l}\text { equipamientos y demás elementos que contribuyan a } \\
\text { reconstruir la ciudad. }\end{array}$ \\
\hline
\end{tabular}

Fuente: elaboración propia.

De esta manera, cada grupo debe identificar elementos a conservar, flujos de circulación y localización de actividades. Todo debe localizarse en el plano: se inicia con ¿qué cosas desean conservar del sector?, posteriormente, con marcadores de diferentes colores, deben identificar los flujos de circulación de los residentes de la zona, la gente que trabaja en la zona, los estudiantes, los turistas y otros flujos. A partir de los flujos identificados, se indaga sobre la posible localización de las actividades que existen y otras que se desea que existan. Cada zona se identificó con papeles de colores sobre el plano (Universidad de los Andes, 2012b).

De igual forma, se hace una exploración sobre la idea de "tipos" de construcciones. Se trabaja con los bloques de madera conformando diferentes formas de edificaciones y ocupación para reflexionar sobre los efectos que tiene en el espacio. Los bloques tienen los mismos colores de los papeles usados para la zonificación de actividades.
Slogan de ciudad. En esta sección se pretende crear un slogan de carácter artístico a partir de los resultados de los talleres de imaginarios sociales en donde plasmen cómo crearían o imaginarían la reconstrucción de ciudad acogiendo elementos como la inclusión social y el desarrollo integral del sector.

Elaboración de esquemas de localización: fallas y recomendaciones de accesibilidad. Una vez realizada la formulación de recomendaciones -tanto generales como especiales- para cada falencia detectada en el diagnóstico, se procede a realizar su localización en un plano (Figs. 7 y 8 ).

Con los resultados del diagnóstico y sus respectivas recomendaciones, a manera de sintesis, se elaboran tablas que numeran y detallan (tramo por tramo) cada una de las fotos de los puntos donde se detectó la falla, su dirección, costado y enfoque (hacia donde mira la foto), diagnóstico (componente analizado y su falla de accesibilidad), las recomendaciones 


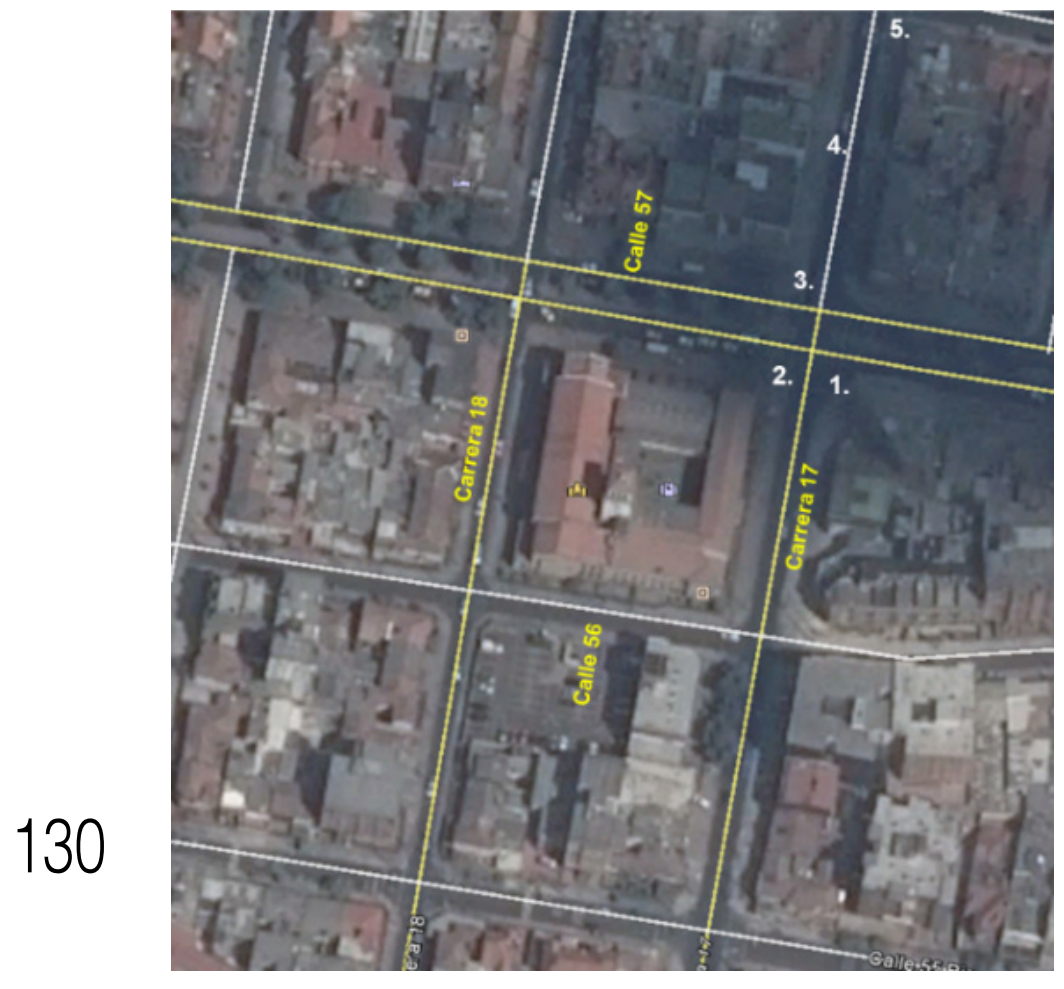

Fig. 7. Plano de localización general de las fallas accesibilidad.

Fuente: elaboración propia.

y su localización general. En la Fig. 9, se puede ver un ejemplo de dichas tablas..

\section{ConcLusiones}

Existe espacio público peatonal construido en Bogotá que no es accesible, por lo tanto, es necesario desarrollar una política pública en urbanismo y accesibilidad que

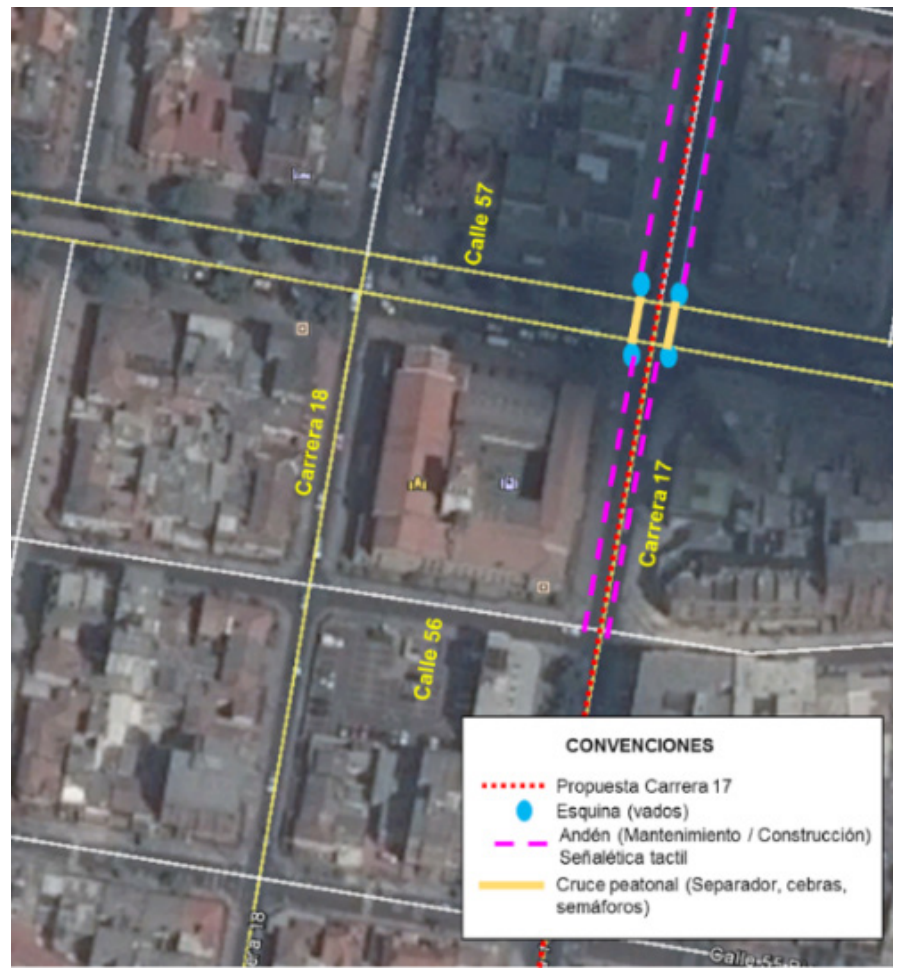

Fig. 8. Plano general de recomendaciones de accesibilidad. Fuente: elaboración propia.

guíe a la ciudad hacia la intervención de estos lugares buscado su rehabilitación, mantenimiento y conservación. Asimismo, se debe conocer los resultados de decálogo de espacios públicos peatonales en el lugar y conocer los resultados de iniciativa de espacios públicos peatonales con los ciudadanos y las entidades públicas y privadas. 


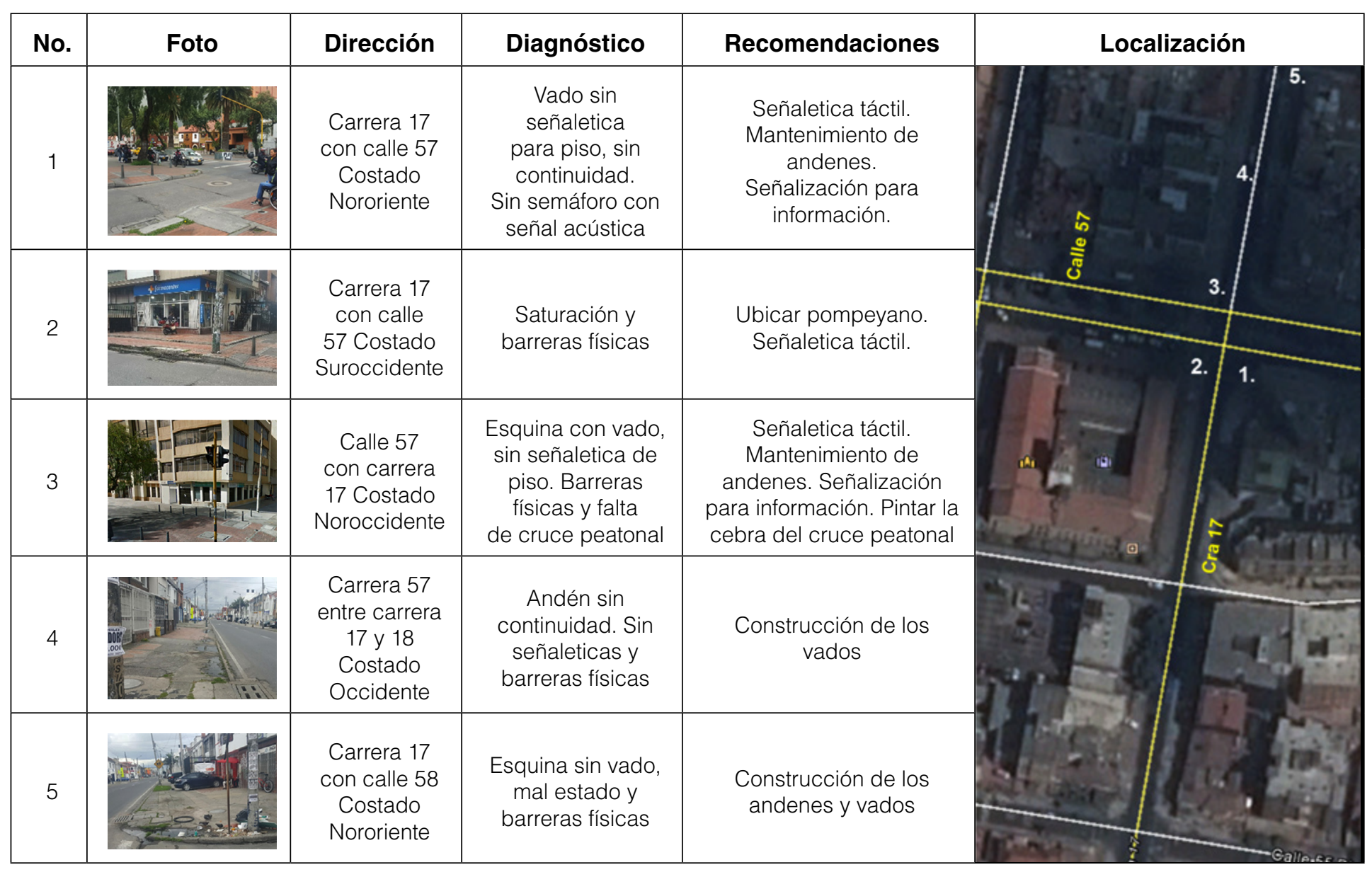

Fig. 9. Tabla con el resumen del diagnóstico y recomendaciones de accesibilidad. 


\section{REFERENCIAS}

Alcaldía de Bogotá. Instituto de Desarrollo Urbano y Secretaria Distrital de Planeación. (2015). Cartilla de andenes Bogotá. D.C. (Taller de Espacio Público). Recuperado de http://www. sdp.gov.co/sites/default/files/cartilla andenes_modificacion_07-06-2018. pdf

Baeza, M. (2004). Ocho argumentos básicos para la construcción de una teoría fenomenológica de los imaginarios sociales. En, Grupo Compostela de Estudio sobre Imaginarios Sociales (G.C.E.I.S.). Seminario Imaginarios Sociales II, Discusiones teóricas contingentes. Concepción, Chile.

Borja, J. (2003). Espacio público y derecho de la ciudad. Barcelona: Electra.

Cañon, L., (2010). Transport and Social Exclusion in Medellin. Potential, Opportunities and Challenges. Londres: Development Planning Unit, University College London.

Comisión de las Comunidades Europeas. (1992). Hacia una Europa de la solidaridad. Intensificación de la lucha contra la exclusión social y la promoción de la integración. Bruselas: COM.

Connell, B. R., Jones, M., Mace, R., Mueller, J., Mullick, A., Ostroff, E., Sanford, J., Steinfeld, E., Story, M. y Vanderheiden, G. (comp.). (1997). Principios de Diseño Universal. Versión 2.0. North Carolina: Centro para el Diseño Universal, NC State University, College of Design.
Corbalán, A. (1 de septiembre de 2014). La ciudad accesible Vs Ciudad ortésica. Recuperado de http://www.accesibilidadglobal.com/2014/09/la-ciudadaccesible-vs-la-ciudad.html

EDU. (2018). Talleres de imaginarios, estrategia de urbanismo cívico - pedagógico, Empresa de Desarrollo Urbano. Medellín: Alcaldía de Medellín, EPM y EDU. Recuperado de http://www.edu. gov.co/site/actualidad/615-gestionsocialuva

Freire, P. (1997). A la sombra de este árbol. Barcelona: El Roure.

Fundación Alejandra Forlán. (Agosto 7 de 2012). Fundación Alejandra Forlán lanza campaña de accesibilidad. El observador. Recuperado de www.elobservador.com.uy/fundacion-alejandra-forlan-lanza-campanaaccesibilidad-n229802

Gobierno de Navarra. (6 de abril de 2010). De accesibilidad universal y diseño para todas las personas. [Ley Foral 5/2010]. Boletín Oficial de Navarra de 14 de abril de 2010; BOE de 26 de mayo de 2010. Recuperado de http://www. navarra.es/nr/rdonlyres/0a87ce14b5b8-470d-81cb-94cf24da8af8/0/ If52010.pdf

InstituteforTransportationandDevelopment Policy, ITDP. (2017). Transit-oriented Development, TOD. Recuperado de https://3gozaa3xxbpb499ejp30lxc8wpengine.netdna-ssl.com/ wp-content/uploads/2017/06/TOD_ printable.pdf 
Molina, L. (2005). La cartografía social y su aplicación a la planificación municipal y regional. Villavicencio: Grupo de estudios urbano regionales del Magdalena Medio Unipaz. Recuperado de http:// www.amigonianos.org/mediateca/ documentos/docs/RutaPedagogicaAmigoniana/los\%20\%20mapas/PON_ CARTOGRAFIA\%20SOCIAL.pdf

Organización Naciones Unidas, ONU. (2006). Convención Internacional sobre los Derechos de las Personas con Discapacidad. Recuperado de www.un.org/esa/ socdev/enable/documents/tccconvs.pdf

Organización de Naciones Unidas, ONU. (1993). Normas uniformes sobre la igualdad de oportunidades para las personas con discapacidad. Recuperado de http://www.un.org/spanish/disabilities/default.asp?id=498

Organización Naciones Unidas, ONU. (1975). Declaración de los derechos de los impedidos. Recuperado de https://documents-dds-ny.un.org/doc/ RESOLUTION/GEN/NR0/783/64/PDF/ NR078364.pdf?OpenElement

Pintos, J. (2004). Inclusión- exclusión. Los imaginarios sociales de un proceso de construcción social. Semana, Ciencias Sociaise Humanidades, 16(1). 17-52.

República de Colombia. Asamblea Nacional Constituyente. (1991). Constitución Política de Colombia. Recuperado de http://www.constitucioncolombia.com/ titulo-2/capitulo-3/articulo-82
República de Colombia. Congreso de la República. (27 de febrero de 2013). Por medio de la cual se establecen las disposiciones para garantizar el pleno ejercicio de los derechos de las personas con discapacidad. [Ley 1618]. Diario Oficial No. 48.717. Recuperado de https://www. minsalud.gov.co/sites/rid/Lists/ BibliotecaDigital/RIDE/DE/PS/documento-balance-1618-2013-240517. pdf

República de Colombia. Alcaldía Mayor de Bogotá. (21 de diciembre de 2015). Por el medio se actualiza la cartilla de andenes adoptada mediante el Decreto Distrital 1003 de 2000, adicionada mediante el Decreto Distrital 379 de 2002 y actualizada mediante el Decreto distrital 602 de 2007, y se dictan otras disposiciones. [Decreto 561]. Registro Distrital 5740. Recuperado de http://www.alcaldiabogota.gov. co/sisjurMantenimiento/normas/ Norma1.jsp?i=64323

República de Colombia. Alcaldía Mayor de Bogotá. (7 de julio de 2005). Por el cual se adoptó el "plan Maestro de Espacio Público para Bogotá Distrito Capital, y se dictan otras disposiciones. [Decreto Distrital 215 ]. Registro Distrital 3356. Recuperado de http://www.alcaldiabogota. gov.co/sisjurMantenimiento/normas/ Norma1.jsp?i=16984 
República de Colombia. Alcaldía Mayor de Bogotá. (28 de diciembre 2007). Por el cual se actualiza la Cartilla de Andenes, adoptada mediante Decreto Distrital 1003 de 2000, y se dictan otras disposiciones. [Decreto Distrital 602 ]. Registro Distrital 3902 Recuperado de http:// www.alcaldiabogota.gov.co/sisjur/ normas/Norma1.jsp?i=28110\&dt=S

Rovira, E. (2003). El libro blanco de la accesibilidad. Barcelona: Edicions Universitat Politécnica de Catalunya, UPC. Recuperado de https://projects.ncsu. edu/design/cud/about_ud/udprinciplestext.htm

Silva, A. (2006). Imaginarios Urbanos. Bogotá, D.C.: Arango.

Townsend, P. (1979). Poverty in the United Kingdom. A survey of household resources and standards of living. Los Angeles: University of California Press.
Universidad de los Andes. (2012a). Progresa Fenicia. Investigación Urbana. Talleres de composición participativa. Recuperado de https:// progresafenicia.uniandes.edu.co/ index.php/el-plan-parcial/38-ccol

Universidad de los Andes. (2012b). Visiones futuras Fenicia. [Video]. Recuperado de https://www.youtube. com/watch?v=58xe934lEfl

Vázquez, F. (2001). La memoria como acción social. Relaciones significados e imaginario. Barcelona: Paidós.

Zetina, N. (coord.). (2013). Carta Mundial por el Derecho a la Ciudad. ONUHabitat. Documentalia; Revista MEC-EDUPAZ, (3), 91-106. 